\title{
Cabotagem como alternativa para o transporte de carnes da região Sul para o Norte/Nordeste brasileiro: um estudo de caso
}

\author{
Arlei Luiz Fachinello ${ }^{1}$ \\ Sidnei Pereira Nascimento ${ }^{2}$
}

Resumo: O custo do transporte de mercadorias é um dos fatores relevantes na competitividade da maioria dos produtos. Visando reduzí-lo, empresas buscam constantemente alternativas mais eficientes para deslocar seus produtos das fábricas até os mercados consumidores. Nesse contexto, este trabalho analisa a viabilidade econômica do transporte de carnes suína e de frango, via cabotagem, da região Sul do Brasil para as regiões Norte e Nordeste. Para isso, utilizou-se um modelo de otimização de custo de transporte por programação linear, focalizando um estudo de caso. Os resultados indicam que os custos de transporte já não são mais restrições ao uso da cabotagem para esse fim.

Palavras-chave: Custo de transporte; carnes; cabotagem.

Abstract: The transportation costs are one of the main factors for companies' competitiveness. In order to decrease the costs, companies are frequently searching for different ways to transport their products to their consumers. This paper analyzes the economic viability of meat transport from the South to the North and Northeast of Brazil, using intercoastal port services. Using a transport cost optimization model and linear programming, our results indicate the economic feasibility of this option.

\footnotetext{
${ }^{1}$ Professor do curso de Economia da Universidade Comunitária Regional de Chapecó. Email: fachinello@hotmail.com

${ }^{2}$ Professor do departamento de Economia na Universidade Estadual de Londrina. Email: sidnei@uel.br
} 
Cabotagem como alternativa para o transporte de carnes da região Sul para o Norte/Nordeste brasileiro: um estudo de caso

Key-words: Transport cost; meat; intercoastal port services.

\section{Classificação JEL: C61.}

\section{Introdução}

O desenvolvimento produtivo de regiões mais distantes dos grandes centros consumidores no Brasil, bem como o aumento dos fluxos de produtos para os portos marítimos, vem demandando meios de transporte mais adequados a essa realidade. A maior parte do transporte interno tem sido realizada via modal rodoviário, mesmo em percursos de grandes distâncias. A tendência observada é de redução dessa parcela, por meio do desenvolvimento de outros modais, assim como da multimodalidade. A regulamentação da Lei $\mathrm{n}^{\circ} 9.611$ em 2004, que criou o operador multimodal, contribuiu para o aprimoramento do carente sistema de transporte do País, inclusive reduzindo gastos com deslocamento dos produtos.

O uso mais eficiente dos modais é uma oportunidade para as empresas se tornarem mais competitivas, por meio da redução de seus custos. Embora não sejam a única motivação das empresas na escolha do modal de transporte, esses gastos continuam sendo um fator relevante na competitividade. Os custos de transporte representam, segundo Bovet e Martin (2000), entre $2 \%$ e $12 \%$ do valor de venda dos produtos, dependendo do setor. Além dos gastos com transporte, os autores citam a velocidade, a confiabilidade e a flexibilidade do sistema de transporte como fatores importantes na opção a ser escolhida, pois possuem estreita relação com os resultados desejados pelas empresas.

Para o setor de carnes, o envio de grandes volumes de produtos frigorificados para regiões consumidoras, distantes do local de produção, ocorre especialmente pelo fato de a produção nacional estar concentrada em determinadas praças. No Brasil, tem-se a região Sul como a principal produtora de aves e suínos, apresentando um elevado excedente produtivo. Já no Norte e Nordeste, o consumo desses produtos é maior que a oferta, o que induz um constante fluxo entre essas regiões ${ }^{3}$.

\footnotetext{
${ }^{3}$ No trabalho de Helfand e Rezende (1998), os autores dimensionaram os fluxos de carnes interestaduais e concluíram que a região Nordeste é deficitária na produção
} 
Esses produtos são transportados exclusivamente pelo modal rodoviário e, em alguns casos, chegam a percorrer mais de $4.500 \mathrm{~km}$ em uma única rota. $\mathrm{O}$ aprimoramento do sistema de cabotagem (transporte marítimo realizado entre dois portos da costa de um mesmo país ou entre um porto costeiro e um fluvial) vem surgindo como uma alternativa para o transporte de carnes da região produtora até os mercados consumidores mais longínquos. Praticamente todas as capitais da região Nordeste do País se localizam no litoral, o que beneficia esta alternativa de transporte. Os entraves vêm sendo eliminados, criando-se condições econômicas mais favoráveis para seu uso.

Partindo desse contexto, este ensaio visa avaliar a possibilidade de incluir a cabotagem como complementação no transporte de carnes suína e de frango entre as regiões Sul e Norte/Nordeste. Para isso, busca-se analisar os fluxos reais dos produtos carnes de aves e suína entre as sete fábricas da empresa Cooperativa Central Oeste Catarinense Aurora, localizadas no Sul do País, e seus mercados no Norte e Nordeste, utilizando-se a técnica de minimização de custos de transporte por programação linear.

\section{Sistema de transporte agroindustrial no Brasil}

A logística é conceituada como sendo todas as atividades de movimentação e armazenagem que facilitam os fluxos de produtos do ponto de aquisição da matéria-prima até o ponto de consumo final. Suas atividades primárias são: transportes, manutenção de estoques e processamento de pedidos. O transporte trata da movimentação das matérias-primas e produtos finais e é responsável pela maior parcela dos custos logísticos. Por essa razão, existe uma preocupação contínua com a redução de seus custos (ANTT, 2004a).

Entre as várias modalidades de transporte, em 2003, o modal rodoviário foi responsável pela maior parcela do fluxo efetuado, $63 \%$. O modal ferroviário representou $24 \%$ e o aquaviário, $13 \%$. A concentração do transporte por rodovias vem sendo reduzida em função do

de carne tanto de frango como suína. Aproximadamente $10 \%$ da demanda de carne de frango e $13,7 \%$ da de carne suína é atendida pela produção de outros estados. No Norte, o déficit ocorre na carne de frango. Já a região Sul é a que apresenta o maior excedente produtivo dos dois tipos de carne. 
Cabotagem como alternativa para o transporte de carnes da região Sul para o Norte/Nordeste brasileiro: um estudo de caso

processo de concessão da Rede Ferroviária Federal, privatização de rodovias e investimentos público e privado no sistema fluvial de diversas regiões do País.

O aprimoramento no sistema logístico tende a diminuir a utilização do uso das rodovias e aumentar o transporte fluvial, criando também melhores condições para o uso da intermodalidade ou multimodalidade. Segundo Costa e colaboradores (2001), a multimodalidade permite que se minimizem os custos unitários de transporte na medida em que combina os diversos modais. Isto foi viabilizado pela Lei $\mathrm{n}^{\circ} 9.611^{4}$, que estabeleceu a figura do operador multimodal e reduziu a burocracia no sistema de transporte. Essa lei permite que as empresas passem a utilizar modais diferentes, fazendo uso de um mesmo documento de conhecimento, o que não era possível até então.

Esse aprimoramento do sistema, ao diminuir os custos de transporte por cabotagem, abre espaço para que mais empresas utilizem esse modal.

\subsection{Transporte rodoviário e de cabotagem no Brasil}

A concentração do transporte de mercadorias por rodovias no País está associada à implantação da indústria automobilística durante as décadas de 60 e 70. Esse comportamento se observou em nível mundial, iniciado na década de 50, especialmente vinculado aos baixos custos do combustível (Schroeder; Castro, 1996). Assim, dadas as características do modal rodoviário, o mesmo atendeu às necessidades do País durante algumas décadas.

Segundo Nazário (2000), o modal rodoviário apresenta custos fixos baixos e custo variável médio. Sua preferência também está em função da maior disponibilidade, velocidade, freqüência e flexibilidade comparativamente a outros modais. Além disso, segundo Oliveira e CaixetaFilho (2001), ele tem a capacidade de ajustar-se mais facilmente às

\footnotetext{
${ }^{4}$ A Agência Nacional de Transportes Terrestres (ANTT) publicou no Diário Oficial da União, em 23 de novembro de 2004, a Resolução $n^{\circ} 794$, que regulamenta a habilitação do Operador de Transporte Multimodal (OTM). A lei foi criada em 1998, porém só foi regulamentada em 2004. Segundo a Lei $\mathrm{n}^{\circ}$. 9.611, o transporte Multimodal de Carga é "aquele regido por um único contrato, utiliza duas ou mais modalidades de transporte, desde a origem até o destino, e é executado sob a responsabilidade única de um Operador de Transporte Multimodal (OTM)” (ANTT, 2004b).
} 
variações na demanda e permite que empresas individuais entrem e saiam da atividade facilmente, ajustando seu investimento às exigências do mercado consumidor.

Essas vantagens, no entanto, vêm sendo deterioradas pela falta de investimentos em infra-estrutura no País e pelo crescimento das necessidades para fazer frente à elevação dos fluxos comerciais entre regiões. Houve deterioração da malha rodoviária existente, sem que houvesse crescimento do transporte não-rodoviário de forma a substituí-lo. Esse sistema de transporte também foi prejudicado pelo aumento dos acidentes e roubos de carga, gerando prejuízos para muitos setores e aumento de custos para todo o sistema transportador rodoviário.

Além da deterioração, o sistema rodoviário tem a desvantagem de não ser o mais adequado para o transporte de grandes distâncias, apesar de ser utilizado no Brasil. Segundo Aslog (1997 apud Caixeta-Filho, 2001), o transporte rodoviário seria indicado para distâncias até 500 km, o ferroviário, entre 500 e 1.200 km, o hidroviário, para distâncias superiores a $1.200 \mathrm{~km}$.

Com o desgaste das vantagens do modal rodoviário e criação de melhores condições para o uso da cabotagem, esta última começa a se tornar uma alternativa economicamente viável e segura para a distribuição das cargas no País.

A costa brasileira possui extensão de $7.408 \mathrm{~km}$; no entanto, vem sendo utilizado muito pouco o transporte aquaviário ${ }^{5}$ no País, especialmente de cabotagem. O cenário desfavorável para a cabotagem foi sendo construído a partir da década de 30 , período em que este modal era o principal meio de transporte de carga. Nas décadas de 50 e 60, com a vinda das indústrias automobilísticas para o País e as atenções voltadas para o transporte rodoviário, os recursos para o transporte aquaviário praticamente se extinguiram (ONO, 2001).

No entanto, com as novas exigências do mercado e as necessidades do País, a demanda por um sistema de transporte mais econômico e adequado tem induzido o aprimorando do sistema aquaviário, em especial a cabotagem. Segundo Carlos Ebner, presidente da empresa de transporte marítimo Docenave, o processo burocrático no sistema ainda di-

${ }^{5}$ Inclui o transporte por cabotagem (navegação costeira), lacustre (em lagos) e fluvial (em rios). 
ficulta o transporte por cabotagem, mas esforços para agilizar e reduzir os custos burocráticos estão sendo empregados. A redução do tempo de embarque e desembarque, a simplificação de processos burocráticos, o atendimento nos portos 24 horas para embarque e desembarque e na fiscalização dos órgãos federais em período integral já seriam suficientes para atender à crescente demanda sem a necessidade imediata da construção de novas embarcações (Revista Tecnologística, 2004).

Entre as vantagens do sistema de cabotagem estão os menores custos e riscos de acidentes e roubos. Segundo Carlos Nóbrega, da Associação Nacional de Transportes Aquaviários, o custo do frete por cabotagem pode ser menor de $15 \%$ a $50 \%$ que o rodoviário, dependendo do produto, origem e destino. Quanto a acidentes e roubos, segundo Jorge Nassar, diretor da operadora de transporte marítimo Aliança, esse aspecto tem sido um importante atrativo da cabotagem em relação ao transporte rodoviário (ABTC, 2002).

Embora o setor demonstre claramente uma tendência de crescimento, ainda se faz necessário transpor várias barreiras que se demonstram de difícil resolução, principalmente no curto prazo, tais como: baixa produtividade dos portos, comparado a outros países; elevados percentuais de encargos sociais; falta do serviço de carga fracionada; burocracia pública e carência de navios e de contêineres para cabotagem.

Para Thomas (2005), entre as principais desvantagens da cabotagem, frente a outras modalidades de transporte, estão a baixa regularidade, o tempo de viagem e a pouca flexibilidade existente. Tais fatores são importantes para a decisão das empresas quanto ao modal de transporte a ser utilizado. Conforme destacam Bovet e Martin (2000), existe uma estreita relação entre a velocidade, a confiabilidade e a flexibilidade do transporte e os resultados desejados pelas empresas.

Para estimular a navegação de cabotagem no País, uma das medidas que estão sendo estudadas é a redução do custo de abastecimento dos navios em comparação com o óleo diesel utilizado pelos caminhões. Há também estudos de adequação e regulamentação da legislação, o estímulo à ampliação e modernização da indústria de construção naval e a reorganização portuária (Secretaria Especial de Portos apud CMA CGM do Brasil, 2008). 


\section{Metodologia}

\subsection{Modelo de otimização de custo de transporte}

O modelo aplicado ao problema foi de otimização linear para custos de transporte. O objetivo é a obtenção das rotas mais econômicas para as carnes transportadas das fábricas até os mercados consumidores. Com isso, pretende-se verificar a viabilidade econômica do transporte de cabotagem para esse fim. O sistema computacional utilizado para os cálculos foi o GAMS (Sistema Geral de Modelagem Algébrica).

Considerando uma empresa produtora de carnes suína e de frango do Sul do País e que comercializa seus produtos com as regiões Norte e Nordeste, são apresentadas na Tabela 1 as cidades em que a empresa possui suas unidades produtivas. Entre as sete fábricas, cinco produzem carne suína e duas, de frango. Além disso, são considerados também 12 centros consumidores, sendo estes as capitais dos estados. As possibilidades de rotas são: rodoviária e marítima (via porto de Santos, via porto de Paranaguá, via porto de Itajaí ou via porto de Porto Alegre).

Tabela 1. Variáveis do modelo

\begin{tabular}{|c|c|c|c|}
\hline Fábricas (i) & $\begin{array}{l}\text { Centros } \\
\text { Consumidores (j) }\end{array}$ & $\begin{array}{l}\text { Caminhos } \\
\text { Possíveis (t) }\end{array}$ & Produtos (p) \\
\hline $\begin{array}{l}\text { 1) Chapecó (SC) } \\
\text { 2) São Miguel do } \\
\text { Oeste (SC) } \\
\text { 3) Joaçaba (SC) } \\
\text { 4) Sarandi (RS) } \\
\text { 5) São Gabriel do } \\
\text { Oeste (MS) } \\
\text { 6) Maravilha (SC) } \\
\text { 7) Quilombo (SC) }\end{array}$ & $\begin{array}{l}\text { 1) Macapá (AP) } \\
\text { 2) Manaus (AM) } \\
\text { 3) Belém (AP) } \\
\text { 4) São Luiz (MA) } \\
\text { 5) Teresina (PI) } \\
\text { 6) Fortaleza (CE) } \\
\text { 7) Natal (RN) } \\
\text { 8) João Pessoa (PB) } \\
\text { 9) Recife (PE) } \\
\text { 10) Maceió (AL) } \\
\text { 11) Aracajú (SE) } \\
\text { 12) Salvador (BH) }\end{array}$ & $\begin{array}{l}\text { 1) Rodoviário } \\
\text { 2) Cabotagem via } \\
\text { Porto de Santos (SP) } \\
\text { 3) Cabotagem via } \\
\text { Porto de Paranaguá (PR) } \\
\text { 4) Cabotagem via Porto de Itajaí (SC) } \\
\text { 5) Cabotagem via } \\
\text { Porto de Porto Alegre (RS) }\end{array}$ & $\begin{array}{l}\text { 1) Carne de } \\
\text { Frango } \\
\text { 2) Carne } \\
\text { Suína }\end{array}$ \\
\hline
\end{tabular}

Fonte: Dados do modelo. 


\section{Índices:}

i representa as 7 unidades fabris da empresa;

j representa os 12 centros consumidores;

t representa as 5 alternativas para o transporte da carga;

p representa os 2 produtos disponíveis para transporte.

cuja função objetivo de minimização do custo total de transporte é:

$$
Z=\sum_{i=1}^{7} \sum_{j=1}^{12} \sum_{t=1}^{5} \sum_{p=1}^{2}\left(C T_{i j t} * X_{i j p}\right)
$$

em que,

$\mathrm{CT}_{\mathrm{ijt}}$ é o valor do frete da origem i para o destino $\mathrm{j}$ pelo meio de transporte t, em toneladas;

$\mathrm{X}(\mathrm{i}, \mathrm{j}, \mathrm{t}, \mathrm{p})$ é a quantidade de carnes do tipo $\mathrm{p}$ transportada da fábrica i para o mercado j, via meio de transporte $t$, em toneladas;

As restrições do modelo são:

a) Quantidade de produto p transportada da fábrica i para os destinos $\mathrm{j}$, via meio de transporte, $\mathrm{t}$ deve ser menor ou igual à capacidade da fábrica i para o produto $\mathrm{p}$.

$$
\sum_{j=1}^{12} \sum_{t=1}^{5} X_{y p p} \leq P R O i p, \text { para todo i e p. }
$$

em que,

$\mathrm{PRO}_{\mathrm{ip}}$ representa a produção do produto $\mathrm{p}$ na fábrica $\mathrm{i}$

b) Quantidades transportadas das fábricas i, todos os produtos p e todos os meios de transporte t para o centro consumidor $\mathrm{j}$ devem ser maiores ou iguais à demanda do mercado $\mathrm{j}$ pelo produto $\mathrm{p}$.

$$
\sum_{i=1}^{7} \sum_{t=1}^{5} X_{i j p} \geq D M \quad j p \text {, para todo je p. }
$$

em que,

$\mathrm{DM}_{\mathrm{jp}}$ é a demanda do centro consumidor j pelo produto $\mathrm{p}$; 
c) Não-negatividade das variáveis.

$$
X_{i j p p} \geq 0 \text {, para todo i, j,t e p. }
$$

\subsection{Oferta e demanda de carnes para as capitais do Norte e Nordeste}

Os dados de produção das sete fábricas se referem ao total de carnes in natura produzido no ano de 2003. Quanto à demanda de carnes da empresa nas 12 capitais selecionadas, decidiu-se estimá-la, uma vez que tais informações não estão disponíveis.

Para a estimativa de demanda por carne suína, foi obtida a população dos municípios em $2003^{6}$ e multiplicada pelo consumo per capita do mesmo ano. Dessa forma, para as cidades do Nordeste, utilizou-se o consumo per capita de $5,5 \mathrm{~kg} / \mathrm{habitante} / \mathrm{ano}$ e para as do Norte, de $3,5 \mathrm{~kg} / \mathrm{habitante} / \mathrm{ano}$ (Rorato, 2003). Do consumo total de carne suína, extraiu-se $7,18 \%$, percentual este que corresponde à participação da empresa na produção nacional nesse setor em $2003^{7}$.

O mesmo procedimento foi realizado para estimar a demanda por carne de frango. Como o consumo per capita por estado está disponível em IBGE (2003), utilizou-se esse referencial. Do consumo total de carne de frango no município, extraiu-se $2,33 \%$. Esse percentual corresponde à parcela do mercado brasileiro que a empresa abasteceu em 2003. A oferta de cada unidade produtiva e as estimativas de demanda para cada região de consumo são apresentadas na Tabela 2.

\footnotetext{
${ }^{6}$ A população municipal de 2003 é a projetada para esse ano. A partir do Censo Populacional de 2000 para as capitais em questão, foi incluído o crescimento populacional estimado para os três anos seguintes (IBGE, 2000).

7 Segundo Abipecs (2003), a empresa Cooperativa Central Oeste Catarinense Aurora teve participação, em 2003 , de $7,18 \%$ e $2,33 \%$ na produção de carne suína e de frango, respectivamente, para o mercado nacional.
} 
Tabela 2. Oferta e demanda estimadas de carnes da empresa nas cidades selecionadas em 2003 (em toneladas)

\begin{tabular}{l|c|c|c|c|c}
\hline \multicolumn{2}{c}{ Demanda de carnes da empresa } & \multicolumn{3}{c}{ Oferta de carnes da empresa } \\
\hline Capitais & Suína & Frango & Fábricas & Suína & Frango \\
\hline Macapá (AP) & 79,7 & 223,1 & Chapecó (SC) & 95.666 & - \\
Manaus (AM) & 381,5 & 672,3 & São Miguel do Oeste (SC) & 36.559 & - \\
Belém (PA) & 342,6 & 531,2 & Joaçaba (SC) & 27.406 & - \\
São Luiz (MA) & 357,9 & 219,4 & Sarandí (RS) & 26.612 & - \\
Teresina (PI) & 291,1 & 238,0 & São Gabriel do Oeste (MT) & 26.910 & - \\
Fortaleza (CE) & 885,1 & 801,4 & Maravilha (SC) & - & - \\
Natal (RN) & 293,3 & 223,1 & Quilombo (SC) & & \\
João Pessoa (PB) & 241,7 & 154,3 & & & \\
Recife (PE) & 580,4 & 447,3 & & & \\
Maceió(AL) & 326,4 & 237,0 & & & \\
Aracajú (SE) & 192,0 & 176,0 & & & \\
Salvador (BH) & 994,1 & 676,5 & & & \\
\hline
\end{tabular}

Fonte: Elaboração dos autores.

\subsection{Composição dos custos de frete}

\subsubsection{Rodoviário}

Os valores de frete por percurso para o transporte de uma carreta de 27 toneladas de carne de Chapecó (SC) para os municípios consumidores foram obtidos junto a algumas transportadoras (prestadoras de serviço para a empresa selecionada). A partir desses dados, foi calculado o custo por quilometragem por carreta, utilizando tal valor como referencial para todas as demais localidades.

Cabe ressaltar que as demais cidades em que a empresa tem abatedouros são, relativamente, próximas à cidade referência (Chapecó), e 
isso faz com que os valores de frete não sejam muito diferentes. Mesmo para o município mais distante, São Gabriel do Oeste (MS), foi consultada uma transportadora de carnes frigorificadas, que confirmou os valores sugeridos como sendo muito próximos da sua realidade, o que revela que assumir o mesmo custo de transporte por quilometragem para todas as cidades ofertantes não é uma hipótese demasiadamente forte.

Tendo os valores de frete por quilometragem para uma carreta de 27 toneladas de carga e as distâncias rodoviárias entre as origens e destinos, obtidas através do Roteirizador MapLink (2004), o valor de frete utilizado na simulação foi obtido pela multiplicação da quilometragem pelo custo por quilômetro da carreta.

\subsubsection{Cabotagem}

Os custos do transporte pelo sistema multimodal rodo/cabotagem foram calculados a partir de informações fornecidas pelas companhias de cabotagem, Docenave (Machado, 2004) e Mercosul Line (Ferreira, 2004). Pelos valores informados, calculou-se a sua média aritmética. O resultado dessa operação forneceu o custo porto-a-porto, em que estão incluídas as despesas portuárias e aluguéis dos contêineres. A esses custos somaram-se os valores de frete rodoviário da fábrica-porto e porto-consumidor, obtendo-se, então, o custo porta-a-porta.

Para a seleção dos portos de origem e destino, utilizou-se o critério de maior proximidade das fábricas e dos mercados consumidores. Entretanto, as empresas de cabotagem utilizadas como referência não necessariamente operam em todos os portos selecionados. Ao menos uma das companhias opera nos portos selecionados, e os custos totais envolvem os seguintes procedimentos:

a) carregamento (estufagem) do contêiner na fábrica e o seu transporte rodoviário até o porto, incluindo o retorno do caminhão com outro contêiner vazio para a fábrica;

b) processo de armazenagem e carregamento do contêiner no navio (custos portuários);

c) deslocamento da embarcação em uma rota com escalas em portos antecessores ao porto de destino; 
d) transbordo do contêiner no porto de destino da embarcação para o veículo rodoviário (custos portuários);

e) deslocamento do caminhão até o consumidor final para o descarregamento do contêiner (desova) e

f) deslocamento do contêiner vazio até o porto.

\section{Resultados e discussões}

Inicialmente, foi simulado o transporte de carnes para seus destinos totalmente via modal rodoviário, visando estimar os custos decorrentes da não-utilização do modal cabotagem (situação vigente). Obteve-se um custo total de transporte na magnitude de $\mathrm{R} \$ 3.250 .487,45$, correspondente ao envio de 4.965 toneladas de carne suína e 4.599 toneladas de frango. Com esse resultado, todos os mercados consumidores seriam abastecidos por apenas duas fábricas. A carne suína seria produzida e enviada de São Gabriel do Oeste (MS) e a carne de frango, de Quilombo (SC). Cabe ressaltar que, na prática, um determinado produto sai de diversas fábricas, muitas vezes em função de sua diferenciação e características aqui não consideradas.

Em seguida, foi realizada a simulação, permitindo que todas as 7 fábricas fossem possíveis fornecedoras, como também os 5 caminhos ( 1 rodoviário e 4 rodo/cabotagem) disponíveis no modelo. O resultado, otimizando o custo total de frete, pode ser visualizado na Tabela 3. Observa-se que o fornecimento de carne suína ocorreria pelas fábricas de Joaçaba $(58,4 \%)$ e São Gabriel do Oeste $(41,6 \%)$. Já o fornecimento de carne de frango seria totalmente via fábrica de Quilombo. No conjunto das carnes, 30,3\% das cargas sairiam de Joaçaba, 21,6\% , de São Gabriel do Oeste, e 48,1\%, de Quilombo. 
Tabela 3. Volume de cargas transportadas das origens para os destinos (em toneladas)

\begin{tabular}{|c|c|c|c|c|c|c|c|c|}
\hline $\begin{array}{l}\text { Origens } \\
\text { Destinos }\end{array}$ & Chapecó & $\begin{array}{c}\text { São M. } \\
\text { Oeste }\end{array}$ & Joaçaba & Sarandi & $\begin{array}{l}\text { São G. } \\
\text { Oeste }\end{array}$ & Maravilha & Quilombo & Total \\
\hline Macapá (AP) & & & & & 79,7 & & 223,1 & 302,8 \\
\hline Manaus (AM) & & & 381,5 & & & & 672,3 & w1.053,8 \\
\hline Belém (PA) & & & & & 342,6 & & 531,2 & w873,8 \\
\hline São Luiz (MA) & & & & & 357,9 & & 219,4 & 577,3 \\
\hline Teresina (PI) & & & & & 291,1 & & 238,0 & 529,1 \\
\hline Fortaleza (CE) & & & 885,1 & & & & 801,4 & $1.686,5$ \\
\hline Natal (RN) & & & 293,3 & & & & 223,1 & 516,4 \\
\hline João Pessoa (PB) & & & 241,7 & & & & 154,3 & 396,0 \\
\hline Recife (PE) & & & 580,4 & & & & 447,3 & $1.027,7$ \\
\hline Maceió (AL) & & & 326,4 & & & & 237,0 & 563,4 \\
\hline Aracajú (SE) & & & 192,0 & & & & 176,0 & 368,0 \\
\hline Salvador (BA) & & & & & 994,1 & & 676,5 & $1.670,6$ \\
\hline Total & 0 & 0 & $2.900,4$ & & $2.065,4$ & & $4.599,6$ & $9.565,4$ \\
\hline Part. \% Total & $0,0 \%$ & $0,0 \%$ & $30,3 \%$ & $0,0 \%$ & $21,6 \%$ & $0,0 \%$ & $48,1 \%$ & $100,0 \%$ \\
\hline Part. \% Produto & $0,0 \%$ & $0,0 \%$ & $58,4 \%$ & $0,0 \%$ & $41,6 \%$ & $0,0 \%$ & $100,0 \%$ & \\
\hline
\end{tabular}

Fonte: Resultados da simulação.

Quanto aos caminhos (rotas) utilizados, observa-se que 43,6\% da carga total seria transportada via modal rodoviário e sairia das cidades de São Gabriel do Oeste e Quilombo (Tabela 4). O restante utilizaria o modal rodo/cabotagem, e os portos de saída seriam Paranaguá, com $3,85 \%$ das cargas, e Itajaí, com 52,5\% das cargas. Aproximadamente $56 \%$ das carnes seriam transportadas utilizando a intermodalidade rodoviário/cabotagem. 
Tabela 4. Volume de cargas por opções de transporte (em toneladas)

\begin{tabular}{|c|c|c|c|c|c|c|c|}
\hline & Rodoviário & $\begin{array}{c}\text { Rodo/ } \\
\text { Cabotagem } \\
\text { Santos }\end{array}$ & $\begin{array}{l}\text { Marítimo } \\
\text { Paranaguá }\end{array}$ & $\begin{array}{c}\text { Marítimo } \\
\text { Itajaí }\end{array}$ & $\begin{array}{c}\text { Marítimo } \\
\text { Porto } \\
\text { Alegre }\end{array}$ & Total & Part. \% \\
\hline Chapecó & & & & & & 0 & $0,0 \%$ \\
\hline São M. Oeste & & & & & & 0 & $0,0 \%$ \\
\hline Joaçaba & & & 192,0 & $2.708,4$ & & $2.900,4$ & $30,3 \%$ \\
\hline Sarandi & & & & & & 0 & $0,0 \%$ \\
\hline São G. Oeste & $2.065,4$ & & & & & $2.065,4$ & $21,6 \%$ \\
\hline Maravilha & & & & & & 0 & $0,0 \%$ \\
\hline Quilombo & $2.111,3$ & & 176,0 & $2.312,3$ & & $4.599,6$ & $48,1 \%$ \\
\hline Total & $4.176,7$ & 0 & 368,0 & $5.020,7$ & 0 & $9.565,4$ & $100,0 \%$ \\
\hline Part, \% & $43,6 \%$ & $0,0 \%$ & $3,8 \%$ & $52,5 \%$ & $0,0 \%$ & $100,0 \%$ & \\
\hline
\end{tabular}

Fonte: Resultados da simulação.

O custo total com o transporte das cargas seria de $\mathrm{R} \$ 2.850 .444,10$. Este valor é $12,3 \%$ menor que o custo da primeira simulação (R\$ $3.250 .487,45)$, na qual toda a carga seria transportada pelo modal rodoviário. Estes resultados demonstram que, pela minimização de custos de transporte, a utilização da intermodalidade rodo/cabotagem é mais vantajosa.

Embora os resultados apresentados sejam um indicativo de que o uso da cabotagem pode ser uma alternativa mais econômica para o transporte de carnes da região Sul para o Norte e Nordeste brasileiro, os custos de transporte podem sofrer alterações. Para dar maior sustentação aos resultados obtidos, decidiu-se simular diversos cenários em que os custos relativos são alterados. Para tanto, foram simulados aumentos de $10 \%$ e $20 \%$ nos custos iniciais. Cabe ressaltar que o aumento do custo de uma alternativa é o mesmo que reduzir a outra. Na Tabela 5, são apresentados os resultados. 
Tabela 5. Volume de carga transportada diante de elevações nos custos de transporte rodoviário (em toneladas)

\begin{tabular}{|c|c|c|c|c|c|c|}
\hline & \multicolumn{2}{|c|}{ Situação normal } & \multicolumn{2}{|c|}{ Aumento de $10 \%$} & \multicolumn{2}{|c|}{ Aumento de $20 \%$} \\
\hline & Rodoviário & $\begin{array}{c}\text { Rodo/ } \\
\text { Cabotagem }\end{array}$ & Rodoviário & $\begin{array}{c}\text { Rodo/ } \\
\text { Cabotagem }\end{array}$ & Rodoviário & $\begin{array}{c}\text { Rodo/ } \\
\text { Cabotagem }\end{array}$ \\
\hline \multicolumn{7}{|l|}{ Chapecó } \\
\hline \multicolumn{7}{|l|}{ São M. Oeste } \\
\hline Joaçaba & & $2.900,4$ & & $3.894,5$ & & $4.607,9$ \\
\hline Sarandi & & & & 357,9 & & 357,9 \\
\hline São G. Oeste & $2.065,4$ & & 713,4 & & & \\
\hline Maravilha & & & & 219,4 & & 219,4 \\
\hline Quilombo & $2.111,3$ & $2.488,3$ & 754,3 & $3.625,9$ & & $4.380,2$ \\
\hline Total & $4.176,7$ & $5.388,7$ & $1.467,7$ & $8.097,7$ & & $9.565,4$ \\
\hline Part. \% Total & $43,7 \%$ & $56,3 \%$ & $15,3 \%$ & $84,7 \%$ & $0,0 \%$ & $100,0 \%$ \\
\hline Part. \% Suíno & $41,6 \%$ & $58,4 \%$ & $14,4 \%$ & $85,6 \%$ & $0,0 \%$ & $100,0 \%$ \\
\hline Part. \% Frango & $45,9 \%$ & $54,1 \%$ & $16,4 \%$ & $83,6 \%$ & $0,0 \%$ & $100,0 \%$ \\
\hline
\end{tabular}

Fonte: Resultados da simulação.

Constata-se que um aumento de $10 \%$ no custo do transporte rodoviário elevaria a parcela da carga transportada pelos modais rodo/ cabotagem, passando de $56,3 \%$ na situação normal para $84,7 \%$ das cargas. Em termos de produto, tanto para a carne suína como para a de frango, haveria uma maior concentração do transporte através da intermodalidade. No caso da carne suína, o transporte via modalidade rodo/cabotagem passaria de $58,4 \%$ para $85,6 \%$. Essa concentração do envio de carne suína via modais rodo/cabotagem implicaria uma maior utilização da fábrica de Joaçaba e uma menor de São Gabriel do Oeste. Já para a carne de frango, a fábrica de Maravilha também passa a direcionar 219,4 toneladas de sua produção para os centros consumidores estudados. O custo total, considerando um aumento de $10 \%$ no custo rodoviário, passaria para $\mathrm{R} \$ 2.933 .933,66$, valor $2,93 \%$ maior que a situação sem o aumento. 
Para a simulação considerando aumento de $20 \%$ nos custos rodoviários, o transporte de carnes seria totalmente realizado pelos modais rodo/cabotagem. A produção e o envio de carne suína ficariam a cargo das unidades de Joaçaba e Sarandi, e a carne de frango ficaria de Maravilha e Quilombo. Nessa simulação, o custo se elevaria em 5,01 \%, passando para $\mathrm{R}$ \$2.993.392,01, quando comparado com a simulação sem aumento de preços. Nas duas situações apresentadas, o modal rodoviário perderia espaço no transporte de carnes da empresa, visando atender às 12 capitais utilizadas na simulação.

No sentido oposto, foram simulados aumentos de $10 \%$, $20 \%$ e $30 \%$ no valor do custo do transporte intermodal, rodoviário/cabotagem, cujos resultados são apresentados na Tabela 6. Um aumento de $10 \%$ nos custos levaria a um aumento de, aproximadamente, $3 \%$ no uso do modal rodoviário. Assim, 46,7\% de todo o volume de carnes a serem transportadas usariam o modal rodoviário e 53,3\%, o rodo/cabotagem. Para o produto suíno, a fabricação e o envio ficariam a cargo das unidades de São Gabriel do Oeste e Joaçaba, enquanto para a carne de frango, seria unicamente Quilombo. O custo total de frete seria de R\$ $3.002 .845,86$. 
Tabela 6. Volume de carga transportada diante de elevações nos custos de transporte rodo/cabotagem (em toneladas)

\begin{tabular}{c|c|c|c|c|c|c|c|c}
\hline & \multicolumn{2}{|c|}{ Situação Normal } & \multicolumn{2}{|c|}{ Aumento de 10\% } & \multicolumn{2}{c}{ Aumento de 20\% } & \multicolumn{2}{c}{ Aumento de 30\% } \\
\hline & Rodo & $\begin{array}{l}\text { Rodo/ } \\
\text { Cabot. }\end{array}$ & Rodo & $\begin{array}{l}\text { Rodo/ } \\
\text { Cabot. }\end{array}$ & Rodo & $\begin{array}{l}\text { Rodo/ } \\
\text { Cabot. }\end{array}$ & Rodo & $\begin{array}{c}\text { Rodo/ } \\
\text { Cabot. }\end{array}$ \\
\hline
\end{tabular}

Chapecó

São M. Oeste

Joaçaba

$2.900,4$

$2.607,1$

$1.266,6$

381,5

Sarandi

São G. Oeste

$2.065,4$

$2.358,7$

$3.699,2$

$4.584,3$

Maravilha

Quilombo

$2.111,3 \quad 2.488,3$

$2.111,3$

$2.488,3$

$3.125,9$

$1.473,7$

$3.927,3$

672,3

\begin{tabular}{lcccccccc}
\hline Total & $4.176,7$ & $5.388,7$ & $4.470,0$ & $5.095,4$ & $6.825,1$ & $2.740,3$ & $8.511,6$ & $1.053,8$ \\
\hline Part. \% Total & $43,7 \%$ & $56,3 \%$ & $46,7 \%$ & $53,3 \%$ & $71,4 \%$ & $28,6 \%$ & $89,0 \%$ & $11,0 \%$ \\
Part. \% Suíno & $41,6 \%$ & $58,4 \%$ & $47,5 \%$ & $52,5 \%$ & $74,5 \%$ & $25,5 \%$ & $92,3 \%$ & $7,7 \%$ \\
Part. \% Frango & $45,9 \%$ & $54,1 \%$ & $45,9 \%$ & $54,1 \%$ & $68,0 \%$ & $32,0 \%$ & $85,4 \%$ & $14,6 \%$ \\
\hline
\end{tabular}

Fonte: Resultados da simulação.

No segundo cenário, com aumento de $20 \%$, observa-se que o modal rodoviário seria utilizado para o transporte de $71,4 \%$ do volume de carnes visando atender aos mercados analisados. A carne suína continuaria a ser produzida e enviada pelas fábricas de Joaçaba e São Gabriel do Oeste, mas agora com aumento da participação desta última. A intermodalidade rodo/cabotagem seria utilizada para o transporte de $28,6 \%$ do volume de carnes, o que equivale a $1.473,7$ toneladas. $\mathrm{O}$ custo total de frete nesse contexto chegaria a $\mathrm{R} \$ 3.126 .411,63$, valor 9,7\% maior que na situação inicial.

Para o último cenário, em que há um aumento de $30 \%$ nos custos rodo/cabotagem, a participação do modal rodoviário aumentaria, atingindo $89 \%$ das carnes transportadas. Nesta situação, quase o total do volume de carnes passaria a sair da fábrica de São Gabriel do Oeste e Quilombo. O custo total com frete chegaria a $\mathrm{R} \$ 3.193 .578,33$, valor $12 \%$ maior que na situação normal. 


\section{Conclusões}

O Brasil caminha para a incorporação de um modelo multimodal de transporte que permite, uma vez funcionando plenamente, reduzir custos, agilizar o envio dos produtos e reduzir o nível de risco de algumas cargas, entre outros benefícios. Mudanças na matriz de transporte vêm ocorrendo, e alguns setores de atividade econômica já utilizam diversos modais. Este ainda não é o caso do setor de carnes da região Sul do País.

Visando avaliar a viabilidade econômica do transporte de carnes suína e de frango da região Sul do Brasil para o Norte e Nordeste, este trabalho utilizou um estudo de caso de localização e distribuição desses produtos entre as regiões estudadas. Foram também criados diversos cenários, com modificações nos custo de transporte, objetivando solidificar os resultados iniciais.

Os resultados indicam que o custo de transporte já não é mais um empecilho para o uso da multimodalidade rodoviário/cabotagem para o transporte de carnes entre as sete fábricas da empresa e os 12 mercados consumidores estudados. Mesmo para alterações nos valores do frete marítimo de até $30 \%$, o uso da multimodalidade se mostrou viável em termos de custos inferiores.

Dessa forma, a não-utilização da cabotagem como meio de transporte de carnes entre algumas regiões do País sinaliza a relevância dos outros fatores - extra custo - nas decisões das empresas quanto ao meio de transporte a ser utilizado. Entre eles estão a sua disponibilidade, agilidade e flexibilidade, fatores que ainda são deficitários no sistema de cabotagem. Verificou-se que, em alguns trechos, o translado por cabotagem despende o dobro de tempo gasto que o observado com o modal rodoviário.

A fabricação de novos navios e sua utilização no transporte de cabotagem, assim como o aumento da freqüência de rotas atendidas e do transporte fracionado de cargas, tende a reduzir os empecilhos que hoje existem para o envio de carnes via costa brasileira. Esses avanços estão em processo. 


\section{Referências bibliográficas}

ABIPECS. Relatório Anual-2003. Disponível em: < http://www.abipecs. com.br/relatorios.php > . Acesso em: 23 nov. 2004.

ABTC. Cabotagem ganha forma em Manaus. Brasília, 09/12/2002. Disponível em: < http//www.abtc.org.br > . Acesso em: 10 nov. 2004.

ANTT. Perguntas mais freqüentes. Disponível em: < http://www.antt. gov.br/faq/multimodal.asp > . Acesso em: 10 nov. 2004a.

ANTT. Resolução da ANTT Regulamenta Habilitação do OTM. Disponível em: < http://www.antt.gov.br/destaques/otm.asp > . Acesso em: 26 nov. 2004b.

BOVET, David M; MARTIN, Bob W.. Sinal verde para o transporte. HSM Management, n.21, ano 4, julho, agosto, 2000.

CAIXETA-FILHO, J. V. Particularidades das Modalidades de Transporte. In: CAIXETA-FILHO J.V.; GAMEIRO, A. H. (Orgs.). Transporte e logística em sistemas agroindustriais. São Paulo: Atlas, 2001. p. 136 -168.

CMA CGM DO BRASIL. Pouco navio e muito caminhão. Disponível em: < http://www.cma-cgm.com.br/site/html/noticia_detalhe.php?id = 25 > . Acesso em: 03 mar. 2008.

COSTA, F. G. et al. Influência do Transporte no uso da Terra: o caso da Logística de Movimentação de Grãos e Insumos na Amazônia Legal. In: CAIXETA-FILHO J.V.; GAMEIRO, A. H. (Org). Transporte e logística em sistemas agroindustriais. São Paulo: Atlas, 2001. p.22 - 139.

FERREIRA, Ivo. Custo de Transporte por Cabotagem da Empresa Mercosul Line. i.ferreira@douat.com.br. Enviado em 20 nov. 2004.

HELFAND, S.M.; REZENDE ,G.C. de. Mudanças Na Distribuição Espacial da Produção de Grãos, Aves e Suínos no Brasil: O Papel do Centro-Oeste, IPEA: Texto Para Discussão, n. 611, dezembro de 1998.

IBGE. Aquisição alimentar domiciliar "per capita" anual por produtos. Pesquisa de Orçamentos Familiares (POF), 2003. Disponível em: < http://www.ibge.gov.br >. Acesso em: 15 nov. 2004. 
IBGE. Censo Demográfico 2000. Disponível em: < http://www.sidra. ibge.gov.br/bda > . Acesso em: 12/11/2004.

MACHADO, Silvio Luciano. Custos de Transporte por Cabotagem da empresa DOCENAVE. silvio.machado@cvrd.com.br.(05/12/2004).

NAZÁRIO, Paulo. Administração do Transporte. In: FLEURY, P.F.; WANKE, P.; FIGUEIREDO, K.(Orgs.) Logística Empresarial: a Perspectiva Brasileira. São Paulo: Atlas, 2000.

OLIVEIRA, J. C. V.; CAIXETA-FILHO, J.V.. Caracterização das Empresas de Transporte Fluvial de Grãos: um estudo de caso para a hidrovia Tietêparaná. IN: CAIXETA-FILHO J.V.; GAMEIRO, A. H. (Orgs.) Transporte e logística em sistemas agroindustriais. São Paulo:Atlas, 2001. p.88 - 111.

ONO, Ricardo T. Estudo de viabilidade do transporte marítimo de contêineres por cabotagem na costa brasileira. 2001, $151 \mathrm{f}$. Dissertação (Mestrado em Engenharia) - Escola Politénica/Universidade de São Paulo. 2001.

REVISTA TECNOLOGISTICA. O porto-a-porto vira parta-a-porta. São Paulo: Editora Publicare, 2004, ano X, n. 108.

RORATO, Rafael J.. Alternativas de transporte rodo-marítimo na distribuição de cargas frigoríficas no Brasil. 2003, 134 f. Dissertação (Mestrado em Engenharia Civil), Escola de Engenharia de São Carlos/ Universidade de São Paulo 2003.

ROTEIRIZADOR MAPLINK. Disponível em: < http://www.maplink. com.br > . Acesso em: 10 dez. 2004.

SCHROEDER, E.M.; CASTRO, J.C.. Transporte rodoviário de cargas: situação atual e perspectivas. Revista do BNDES, Rio de Janeiro, n. 6, dez. 1996. Disponível em: < http://www.bndes.gov.br/conhecimento/ revista/carga.pdf > . Acesso em: 10 nov. 2004.

THOMAS, Júlio. Desenvolvimento da cabotagem no Brasil, 2005. Disponível em: www.ahk.org.br/extranet/gie/pdf_gie/Cabotagem_Brasil. pdf. Acesso em: 3 abr. 2008. 